\title{
The roles of microRNAs in the regulation of tumor metastasis
}

\author{
Lei Zhou ${ }^{1,2+}$, Fan Liu ${ }^{1,3+}$, Xiaomin Wang ${ }^{*^{*}}$ and Gaoliang Ouyang ${ }^{4^{*}}$
}

\begin{abstract}
MicroRNAs (miRNAs) are small noncoding regulatory RNAs that regulate gene expression post-transcriptionally by either inhibiting protein translation or degrading target mRNAs. The differential expression profiles of miRNAs in different types of cancers and in the multi-step process of tumor progression indicate that miRNAs are involved in tumor onset, growth and progression. Metastasis is the most common cause of cancer-related mortality. Current evidence demonstrates that aberrant miRNA expression promotes or inhibits tumor metastasis by modulating the expression of numerous target genes. Therefore, the identification of metastasis-related miRNAs and a better understanding of the complex functions of miRNAs in tumor metastasis will provide potential diagnostic and prognostic biomarkers, as well as therapeutic targets for clinical application. Here, we review the functions of miRNAs in the control of multiple steps of tumor metastasis.
\end{abstract}

Keywords: microRNA, Cancer, Metastasis, Epithelial-mesenchymal transition, Cancer stem cell

\section{Introduction}

Metastasis remains a major challenge for the clinical management and prognosis of patients with cancer. As the most common cause of cancer-related mortality, metastasis involves several continuous steps through which cancer cells disseminate and spread from a primary tumor to distant sites, forming secondary tumors in other organs and tissues [1-3]. Recent studies have provided exciting new insights into the molecular mechanisms of tumor metastasis; however, research on the functions and mechanisms of microRNAs (miRNAs) in metastasis has only recently begun.

miRNAs are highly conserved, endogenous noncoding RNAs that have been shown to regulate distinct cellular processes by interfering with protein expression at the post-translational level. Specifically, miRNAs modulate gene expression by binding to the 3'-untranslated-region (UTR) of target mRNAs, which have complete or partial complementarity with their seed region. This results in

\footnotetext{
* Correspondence: wxm@xmzsh.com; oygldz@xmu.edu.cn

${ }^{\dagger}$ Equal contributors

${ }^{1}$ Fujian Provincial Key Laboratory of Chronic Liver Disease and Hepatocellular Carcinoma, Zhongshan Hospital, Medical College, Xiamen University, Xiamen 361004, China

${ }^{4}$ State Key Laboratory of Cellular Stress Biology, Innovation Center for Cell Signaling Network, School of Life Sciences, Xiamen University, Xiamen 361102, China

Full list of author information is available at the end of the article
}

impairment of the translation and/or stability of the target mRNAs and the subsequent downregulation of protein expression. Current evidence has demonstrated that many miRNAs that have normal functions in the modulation of physiological processes are deregulated in various pathological processes, including tumor onset, growth and metastasis [4-6]. A single miRNA can function as an oncogene or as a tumor suppressor gene to silence the expression of many target genes and thereby remodel the expression profile of cells. Thus, specific miRNAs can function as promoters or suppressors of metastatic progression and coordinately inhibit numerous target genes in tumor metastasis. Aberrant miRNA expression profile during multi-step metastatic processes is a common characteristic of tumor metastasis $[7,8]$. It was recently discovered that secreted miRNAs have also been found in the serum and other body fluids of individuals with cancer $[9,10]$. Acting in a manner consistent with their primary roles, secretory miRNAs also act as translational inhibitors in recipient cells, which indicates that secretory miRNAs can regulate cellular processes at distant sites during the tumor metastatic cascade. Therefore, miRNAs may be good targets for the modulation of multiple steps of the metastatic cascade. In this review, we focus on the roles of miRNAs in the regulation of tumor metastasis, and 
we discuss the possibility of miRNAs as diagnostic and prognostic biomarkers and therapeutic targets for tumor metastasis.

\section{Functions of miRNAs in the tumor metastatic cascade miRNAs and local invasion}

Some tumors rarely disseminate to distant target sites although they are locally invasive, whereas other tumors are highly aggressive and establish metastatic lesions at secondary sites at a high frequency. To migrate to secondary sites and to flourish in those sites, disseminated tumor cells (DTCs) that have detached from the primary tumor microenvironment must survive a series of steps termed the metastatic cascade. Cancer cell detachment, migration and invasion are early steps in the invasion and metastatic cascade. Current evidence demonstrates that miRNAs play critical roles in tumor cell invasion. miR-10b, which promotes cell migration and invasion, has been identified as a metastasis-promoting miRNA in breast cancer [11]. The silencing of miR-10b reduces mesenchymal subtype-like glioma cell invasion through the suppression of TP53, PAX6, NOTCH1 and HOXD10 [12]. The miR-17-92 cluster is often amplified in cancers. The miR-17-92 cluster member miR-19a/b is highly expressed in gastric cancer tissues and is significantly associated with gastric cancer metastasis. miR-19a/b promotes the migration, invasion and metastasis of gastric cancer cells by targeting MXD1, an antagonist of c-Myc [13]. miR-135b expression is also increased in invasive non-small-cell lung cancer cells. miR-135b promotes cell migration and invasion in vitro and increases cancer metastasis in vivo via the regulation of the Hippo pathway [14]. miR-362-5p is highly expressed in hepatocellular carcinomas (HCCs) and correlates with HCC progression. The inhibition of miR-362-5p in HCC cells suppresses cell proliferation, migration and invasion in vitro and tumor growth and metastasis in vivo [15].

In contrast, some miRNAs are negative regulators of cell invasion. miR-34a and miR-34c are significantly downregulated in metastatic breast cancer. The restoration of miR-34a/c in breast cancer cell lines inhibits cell migration and invasion in vitro and reduces distal pulmonary metastasis in vivo by directly targeting Fra-1 [16]. Androgen-regulated miR-135a inhibits prostate the migration and invasion of cancer cells directly through its downstream targets, ROCK1 and ROCK2 [17]. HMGA1 activates miR-137 transcription by binding to the promoter of miR-137 in colorectal cancer cells, which reduces the level of FMNL2, a downstream target of miR-137. The ectopic expression of miR-137 reduces the invasiveness of colorectal cancer cells [18]. miR-145 attenuates gastric cancer cell migratory and invasive abilities in vitro by targeting $\mathrm{N}$-cadherin (CDH2). Assays to detect experimental and spontaneous metastasis further confirmed that miR-145 suppresses the metastatic cascade in vivo [19]. The overexpression of miR-145 inhibits the invasiveness and metastasis of neuroblastoma cells by targeting HIF-2 $\alpha$ [20]. miR-1 expression is consistently downregulated in primary human prostate tumors and is reduced even more in distant metastases. As a prostate cancer suppressor, miR-1 affects the cellular organization of F-actin and impairs tumor cell invasion and the formation of filopodia [21]. These findings indicate that miRNAs play critical roles in the regulation of local invasion by cancer cells.

The breakdown and remodeling of the extracellular matrix are critical steps in cancer cell invasion. Tenascin $\mathrm{C}$ and other matricellular proteins, such as periostin and osteopontin, play important roles in remodeling the tumor metastatic microenvironment $[22,23]$. The loss of miR-335 expression is related to poor distal metastasisfree survival of patients with breast cancer. The restoration of miR-335 expression suppresses cell migration, invasion and metastasis by targeting tenascin $\mathrm{C}$ and SOX4 in breast cancer [24]. miR-29c, which is downregulated in nasopharyngeal carcinomas, targets several genes that encode extracellular matrix proteins, including multiple collagens and laminin $\gamma 1$; these proteins are associated with increased tumor invasion and metastasis [25]. Therefore, miRNAs are believed to be coordinated regulators of the remodeling of the extracellular matrix during cancer cell invasion.

Many cancer cells undergo epithelial-mesenchymal transition (EMT) to achieve enhanced motility and to gain resistance to apoptosis; however, some cancer cells might undergo collective migration independent of an EMT program. The miR-34/SNAIL and miR-200/ZEB mutual-inhibition feedback circuits contribute to the regulation of epithelial-hybrid-mesenchymal fate determination and collective migration [26]. miR-21 is involved in epithelial collective cell migration [27]. Recently, it was shown that miR-124 directly regulates the stability and translation of integrin $\beta 1 \mathrm{mRNA}$ in order to modulate the intercellular adhesion of the leading cells in tumors during collective invasion [28]. However, little is known at present regarding the role of miRNAs in the regulation of collective migration in the tumor metastatic cascade.

\section{miRNAs and intravasation}

To disseminate to distant sites, invasive cancer cells must enter the circulatory or lymphatic systems or travel across the body cavities. The destruction of vascular endothelial barriers is a critical step for cancer cell intravasation. miR-105 is secreted by metastatic breast cancer cells and promotes metastasis by direct targeting of the tight junction protein $\mathrm{ZO}-1$, which destroys vascular endothelial barriers [29]. Compared with normal breast tissues, miR-21 is highly expressed in breast tumors and 
correlates with advanced stage, lymph node metastasis and reduced survival time. The suppression of miR-21 significantly reduces the invasion and lung metastasis of breast cancer cells by targeting TPM1, PDCD4 and Maspin [30]. In addition to the promotion of cell invasion and proliferation, miR-21 can enhance colorectal cancer cell intravasation by binding to the 3 '-UTR of PDCD4. The downregulation of miR-21 in colorectal cancer cells inhibits invasion, intravasation and lung metastasis [31]. miR-182 is significantly overexpressed in mouse sarcomas that metastasize to the lungs. miR182 deletion decreases circulating tumor cells, whereas miR-182 overexpression increases circulating tumor cells, which indicates that miR-182 promotes the entry of cancer cells into the circulation [32].

The expression of members of the miR-520c/miR-373 family negatively correlates with lymph node metastasis, specifically in ER-negative breast cancers. The miR$520 \mathrm{c} / \mathrm{miR}-373$ family inhibits cell invasion in vitro as well as the intravasation of breast cancer cells in vivo and plays a tumor-suppressive role in ER-negative breast cancers via the regulation of the NF- $\kappa B$ and TGF- $\beta$ pathways [33]. RKIP inhibits breast cancer cell intravasation and bone metastasis in mice in part through a signaling cascade that involves MAPK, Myc, LIN28, let-7 and downstream let-7 targets, which indicates that let-7 may be involved in RKIP-inhibited cell intravasation [34]. These findings have opened new avenues in our understanding of the roles of miRNAs in the regulation of cancer cell intravasation during tumor metastasis.

\section{miRNAs and the systemic circulation}

Anoikis is a special form of programmed cell death that occurs when normal cells detach from the extracellular matrix or from cell-cell anchors and are maintained in suspension. Under normal circumstances, anoikis prevents the attachment of these detached cells to an inappropriate extracellular matrix and prevents the colonization of these cells outside of their usual anatomical site. After they enter the circulation, some cancer cells are destroyed in the bloodstream by shear stress and by anoikis. Therefore, DTCs must still overcome detachment, evade immune attack and survive the sheer forces that they encounter in the circulation. Several lines of evidence have indicated that p53 and various other proteins play important roles in anoikis, which is triggered by a lack of adhesion; however, the specific miRNAs that regulate anoikis in the systemic circulation are unknown.

The level of miR-296-3p is much higher in highly metastatic human prostate cancer cells than in non-metastatic cells. The knockdown of miR-296-3p in metastatic human prostate cancer cells reduces their resistance to natural killer (NK) cells, whereas the ectopic overexpression of miR-296-3p in non-metastatic prostate cancer cells enhances the tolerance of these cells to NK cells. miR296-3p promotes prostate cancer metastasis through an augmentation of the survival of NK cell-resistant circulating tumor cells by targeting ICAM-1 [35]. miR-148b is downregulated in aggressive breast tumors and inhibits multiple steps of tumor progression via the regulation of invasion, resistance to anoikis, extravasation, metastatic colonization in lung and chemotherapeutic response [36]. Although several miRNAs contribute to cell survival and help cells to overcome the shear stress and immune attack, little is known in regards to the molecular mechanisms of miRNAs in the systemic circulation of cancer cells.

\section{miRNAs and extravasation}

For blood vessel-borne metastasis, cancer cells must arrest or adhere to the endothelial lining and then undergo extravasation. As a potent regulator of ZO-1, miR-105 can be expressed and secreted by metastatic breast cancer cells, which can then disrupt the tight junctions of endothelial cells. In endothelial monolayers, exosomal miR-105, which is secreted by breast cancer cells, not only destroys the endothelial barriers in primary sites but also disrupts the tight junctions of endothelial cells in secondary organs, which allows cells to extravasate. miR-105 overexpression in non-metastatic cancer cells promotes vascular permeability and metastasis to distant sites, whereas miR-105 inhibition in highly metastatic tumors alleviates these effects [29]. Thus, miR-105 can efficiently destroy the integrity of vascular endothelial barriers to promote metastasis. miR-155 is frequently highly expressed in several types of human cancers. miR-155-expressing breast tumors are associated with an aggressive malignant phenotype and with poor prognosis [37]. Interestingly, the loss of miR-155 reduced central nervous system extravasation of systemic tracers in mice. Moreover, miR-155 negatively regulates the function of the brain endothelial barrier by through the targeting of the cell-cell complex molecules annexin-2 and claudin-1 and the focal adhesion components DOCK-1 and syntenin-1 [38], which indicates that miR155 may promote cancer cell extravasation during the process of tumor metastasis. miR-214 expression is deregulated in several human tumors. It suppresses cell migration and invasion in vitro and inhibits the metastasis of colorectal cancer to the liver in vivo by targeting FGFR1 [39]. In contrast, miR-214 promotes melanoma metastasis through an enhancement of extravasation [40]. miR-214 overexpression in melanoma cells not only promotes cell migration, invasion and resistance to anoikis in vitro but also promotes extravasation and the formation of lung metastasis in vivo [41].

The expression of miR-31 expression is inversely correlated with metastasis in patients with breast cancer. 
miR-31 represses several metastatic processes, including local invasion, extravasation, initial survival in distant tissues and distant colony formation. The shRNAmediated concurrent suppression of ITGA5, RDX and RhoA is sufficient to phenocopy the influences of miR31 on local invasion, early post-intravasation events and metastatic colonization in vivo [42]. A recent report demonstrates that overexpression of miR-25 in highly metastatic human prostate cancer cells attenuates metastasis via the inhibition of extravasation in vivo by direct targeting of $\alpha v$ - and $\alpha 6$-integrins [43]. These findings suggest that miRNAs can regulate tumor metastasis through the modulation of extravasation.

\section{miRNAs and metastatic colonization}

Metastatic colonization is the key rate-limiting step in the tumor metastasis cascade. The overexpression of miR-200 s correlates with an increased risk of metastasis in breast cancer and augments metastatic colonization in mice partly through the direct targeting of Sec23a [44]. Breast cancer patients with metastasis have a high level of circulating miR-122. Breast cancer-cell-secreted miR-122 promotes metastatic colonization in the brain and lungs of mice and inhibits glucose uptake by niche cells through the targeting of pyruvate kinase. This process results in an increase in glucose that is available to the cancer cells that are undergoing metastasis in premetastatic niches [45].

Profile analyses have revealed that the level of miR-149 is extremely low in basal breast cancer. The expression of miR-149 significantly inhibits basal-like breast cancer cell migration and invasion in vitro and impairs lung colonization in vivo [46]. For successful metastatic colonization in the liver, DTCs must settle and adapt to the unfavorable microenvironment of the liver parenchyma and resume proliferation. The former metastatic steps are relatively easy to overcome because of direct blood circulation via portal veins and because of the porous property of the liver sinusoids. miR-493 inhibits the settlement of colon cancer cells that have metastasized in the liver parenchyma and promotes the death of these cells by targeting IGF1R [47]. miR-148a is abundant in the liver but is dramatically downregulated in HCC tissues. The restoration of miR-148a expression in hepatoma cells markedly inhibits their migration in vitro and their pulmonary metastatic colonization in vivo [48]. Collectively, these findings demonstrate that many miRNAs are involved in the regulation of metastatic colonization.

\section{Functions of miRNAs in EMT during tumor metastasis}

EMT is the critical program that is used by DTCs for invasion and metastasis. In patients with breast cancer, the miR-9 levels in primary tumors from patients with diagnosed metastases are markedly upregulated compared with those from metastasis-free patients. miR-9 can promote the motility and invasiveness of breast cancer cells by targeting $\mathrm{CDH} 1$, the E-cadherin-encoding messenger RNA [49]. A high level of miR-155 is frequently observed in invasive breast cancer tissues. miR-155 knockdown inhibits TGF- $\beta$-induced EMT, dissolution of tight junction, cell migration and invasion [50]. Patients with gallbladder carcinoma with higher miR-20a levels exhibit worse overall survival than those with lower miR-20a levels. miR-20a is closely correlated with local invasion, distant metastasis, and poor prognosis in patients with gallbladder carcinoma. The overexpression of miR-20a in gallbladder carcinoma cells induces EMT and promotes metastasis via the direct inhibition of Smad7 [51].

miR-200 family members are important markers of epithelial cells and are critical master regulators of EMT. Under normal conditions, miR-200 can inhibit the expression of ZEB1 and ZEB2, which promotes an epithelial phenotype and cell adhesion. However, ZEB1 and ZEB2 can be activated by the contextual signals within the tumor microenvironment and can suppress the expression of their own suppressor, miR-200, to promote EMT, invasion and metastasis $[52,53]$. The level of miR203 is extremely low in highly metastatic breast cancer cells, and the overexpression of miR-203 in these cells suppresses cell invasion in vitro and metastatic colonization of the lung in vivo via the targeting of SNAI2. Moreover, miR-203 and SNAI2 inhibit the expression of each other through a negative feedback loop, which modulates EMT and metastasis [54]. miR-124 is frequently downregulated in HCC tissues and is negatively correlated with a poor prognostic phenotype in patients with HCC. The overexpression of miR-124 in HCC cells inhibits EMT and the formation of stress fibers (i.e., filopodia and lamellipodia) in vitro and suppresses intrahepatic and pulmonary metastasis in vivo, most likely by targeting ROCK2 and EZH2 [55]. The expression of miR-612 in patients with HCC is inversely correlated with tumor size, stage, EMT and metastasis. miR-612 contributes to both the initial and final steps of the metastatic cascade by inhibiting local invasion and distant metastatic colonization [56]. miR-125a is a recently identified regulator of myeloid malignancies that targets WT1. miR-125a knockout mice develop myeloproliferative disorders and exhibit urogenital abnormalities [57]. Moreover, miR-125a can inhibit EMT in ovarian cancer cells by targeting ARID3B [58]. Therefore, miRNAs are critical coordinating regulators of EMT during tumor metastasis.

Only a small subset of DTCs has the potential to initiate metastatic growth in a new tissue environment [22]. Once they become established in a new tissue environment, metastatic cancer cells revert to a non-metastatic 
epithelial phenotype via mesenchymal-epithelial transition (MET). Twist1 can induce EMT to facilitate breast cancer cell intravasation into the circulation and the subsequent dissemination of these cells into the lungs. However, for DTCs to proliferate and form metastases at distant sites, Twist1 must be turned off to allow MET to proceed [59]. Interestingly, Twist1 can promote the expression of miR-10b by directly binding to the promoter of miR-10b [11], which indicates that miR-10b may affect the invasion, intravasation, circulation, extravasation and metastatic colonization of breast cancer cells. Recently, miR-424 has been shown to be positively associated with EMT-like phenotypes and with Twist1/2 expression. miR-424 is highly expressed in primary breast tumors compared with matched normal breast tissues; however, miR-424 expression is decreased in metastases compared with matched primary breast tumors [60]. These findings demonstrate that EMT and/or MET are critical programs used by cancer cells for metastasis.

\section{Functions of miRNAs with respect to cancer stem cells in tumor metastasis}

Cancer stem cells (CSCs) are a sub-population of cancer cells that are thought to be responsible for tumor initiation, metastasis, resistance to therapy and relapse $[22,61,62]$. Aberrant expression of miRNAs may play a critical role in the regulation of the characteristics and functions of CSCs in tumor metastasis. The impairment of the miRNA biogenesis gene DICER1 in colorectal cancer cells promotes tumor initiation and metastasis by endowing colorectal cancer cells with stem cell properties and EMT phenotypes [63]. miR-22 overexpression is associated with poor clinical outcomes of breast cancer patients and promotes EMT, invasiveness, stemness and metastasis [64]. A high level of miR-199a correlates with poor survival in patients with breast cancer. Mesenchymal stem/stromal cells promote the aberrant expression of miR-199a in breast cancer cells in a contact-dependent manner. Subsequently, miR-199a inhibits the expression of FOXP2 and endows breast cancer cells with enhanced CSC properties [65]. miR-9 is highly expressed in metastatic human primary squamous cell carcinoma. A high level of miR-9 enhances the expansion and metastasis of squamous cell carcinoma CSCs [66]. Increased miR133 a is significantly correlated with poor prognosis in patients with osteosarcoma. The silencing of miR-133a by locked nucleic acids (LNAs) inhibits the invasiveness of CSCs that express high levels of CD133. The administration of LNAs with chemotherapy synergistically inhibits lung metastasis and prolongs the survival of osteosarcoma-bearing mice [67].

As a key negative regulator of prostate CSCs, miR-34a suppresses prostate CSCs and metastasis by directly targeting CD44 [68]. miR-7 is downregulated in breast CSCs. The overexpression of miR-7 can suppress cell invasion and metastasis through a decrease in the breast CSC population and by a partial reversal of the EMT phenotype in breast cancer cells by targeting SETDB1 [69]. Interestingly, by targeting KLF4, miR-7 overexpression inhibits the ability of breast CSCs to metastasize to the brain [70]. We recently demonstrated that the expression level of miR-33b is extremely low in human breast cancer samples and in highly metastatic breast cancer cell lines. Moreover, miR-33b can reduce the stemness and inhibit the metastasis of breast cancer cells to the lungs through the regulation of HMGA2, SALL4 and Twist1 [71]. Therefore, miRNAs are critical players in the modulation of the stemness of DTCs in the metastatic cascade.

\section{Functions of miRNAs in the metastatic microenvironment}

DTCs at distant sites must evade immune attack or recruit immune/inflammatory cells or other stromal cells and their secreted factors to assist them so that they can adapt and remodel the metastatic microenvironment and complete the subsequent proliferation and colonization steps of the metastatic cascade $[2,10]$.

Portal vein tumor thrombus (PVTT) is highly related to poor prognosis in individuals with HCC. miR-34a can decrease the production of the chemokine CCL22, which recruits regulatory $\mathrm{T}$ cells to facilitate immune escape. Moreover, miR-34a expression can be inhibited by TGF- $\beta$. Interestingly, $\mathrm{HBV}$ infection and the activity of the TGF$\beta$-miR-34a-CCL22 axis predispose HCC patients to the development of PVTT, possibly through the formation of an immune-supportive microenvironment that favors the colonization of disseminated HCC cells in the portal venous system [72]. Recently, miR-34a was identified as a novel suppressor of osteoclastogenesis, bone resorption and the bone metastatic niche. The metastasis of breast and skin cancers to bone is diminished in osteoclastic miR-34a transgenic mice but is exacerbated in miR-34a knockout and heterozygous mice. In addition, miR-34a nanoparticle treatment can attenuate the metastasis of breast and skin cancers to bone. Moreover, miR-34a is downregulated during osteoclast differentiation and is a newly identified suppressor of osteoclastogenesis and bone resorption. Therefore, osteoclastic miR-34a can effectively inhibit malignant progression by disturbing the bone metastatic niche [73]. In addition, the levels of two other osteoclast miRNAs, miR-16 and miR-378, are increased in bone lesions and in serum samples from patients with bone metastasis and correlate with the bone metastasis burden [74]. Thus, these osteoclastic miRNAs are potential biomarkers and therapeutic targets of bone metastasis.

miR-155 is involved in the development and function of immune cells [75]. The knockdown of miR-155 in the 
myeloid compartment of MMTV-PyMT mice significantly promotes tumor growth by impairing the activation of tumor-associated macrophages [76]. Bone marrow that lacks miR-155 significantly promotes lung metastasis but does not have a substantial effect on primary tumor growth. The expression of miR-155 in host immune cells inhibits solid tumor metastasis by regulating the recruitment and polarization of bone marrow-derived macrophages [77]. miR-155 deficiency promotes the growth of melanoma and Lewis lung carcinoma tumors by enhancing the recruitment of myeloid-derived suppressor cells (MDSCs) to the tumor microenvironment [78]. However, a high level of miR-155 in leukemia cells correlates with aggressive disease in patients with chronic lymphocytic leukemia (CLL). miR-155 enhances cell sensitivity to B-cell receptor ligation, which indicates that miR-155 is involved in the regulation of the tumor microenvironment of CLL [79]. Recently, the inhibition of miR-155 by antisense oligomers was used for cancer therapy that was targeted to the tumor microenvironment in a mouse model of lymphoma [80]. MDSCs potently inhibit anti-tumor immune responses and contribute to the formation of a metastatic microenvironment that favors tumor metastasis. The expression of miR-494 promotes the accumulation of MDSCs in tumor tissues. The knockdown of miR-494 reverses the function of MDSCs in tumors and suppresses tumor growth and breast cancer cell metastasis in vivo [81]. MDSCs induce the expression of miR-101 in ovarian cancer cells, which subsequently augments the stemness of cancer cells and enhances their tumorigenic and metastatic potential [82].

Enhanced endothelial recruitment capacity is also a key feature of metastatic breast cancer cell populations. The silencing of miR-126 in breast cancer cells significantly promotes metastatic colonization in multiple organs, such as the lung, brain, bone and liver, via the enhancement of endothelial recruitment. Endogenous miR-126 can inhibit endothelial recruitment, metastatic angiogenesis and metastatic colonization of distant sites by coordinately targeting IGFBP2, PITPNC1 and MERTK [83]. Interestingly, miR-126 and miR-126* target SDF- $1 \alpha$ to suppress breast cancer metastasis through the inhibition of the recruitment of mesenchymal stem cells and inflammatory monocytes [84]. Therefore, the recruitment of endothelial cells, mesenchymal stem cells and inflammatory monocytes, which is regulated by miR-126 and/or miR-126*, may provide incipient metastases with a critical microenvironmental cue that promotes the efficiency of metastatic initiation and results in enhanced metastatic colonization.

DTCs exist in a dormant state when they are in a hostile metastatic microenvironment but may switch from dormancy into proliferative metastatic growth in a supportive microenvironment. Tumor dormancy in metastatic sites can be regulated by intracellular signaling pathways and by extracellular microenvironmental cues $[85,86]$. The exosomal transfer of miR-23b from bone marrow mesenchymal stem cells can promote breast cancer cell dormancy in a metastatic niche, as miR-23b targets MARCKS [87]. The CXCL12-specific miRNAs, including miR-127, $-197,-222$ and -223 , which are transported from bone marrow-derived stromal cells to breast cancer cells via gap junctions or stromal-derived exosomes, promote breast cancer cell quiescence by a decrease in CXCL12 levels. This finding indicates that the transfer of miRNAs from bone marrow stroma to breast cancer cells can regulate the dormancy of metastatic breast cancer cells in the bone marrow [88]. However, to date, few miRNAs that maintain the dormant or active state of DTCs have been identified.

\section{miRNAs as diagnostic and prognostic biomarkers and therapeutic targets for tumor metastasis}

miRNAs that are strongly associated with metastatic phenotypes may be useful as diagnostic or prognostic markers of metastasis. The overexpression of miR-103 and miR-107 in a mouse model of colorectal cancer was shown to promote local invasion and liver metastasis by targeting DAPK and KLF4. The signature of a high miR103/107, low DAPK and low KLF4 expression profile correlates with the extent of lymph node and distant metastasis in patients with colorectal cancer. Thus, miR103 and miR-107 can be used as prognostic markers for metastatic recurrence and for poor survival in patients with colorectal cancer [89]. The expression of miR-340 is significantly decreased in bone marrow cells of colorectal cancer patients with liver metastasis. Thus, miR-340 may be a novel prognostic factor and a therapeutic target for colorectal cancer [90]. The overexpression of miR-630 in breast cancer cells that are resistant to HER-targeted drugs significantly restores the efficacy of those drugs (e.g., lapatinib, neratinib and afatinib), which indicates that miR-630 can be used as a diagnostic and predictive marker to gauge the treatment response to HER-targeted drugs [91]. Further research in regards to miRNAs will facilitate the accurate and early identification of DTCs, will provide tractable targets for the monitoring of minimal residual disease and will help predict responses to treatment that is aimed at the prevention of metastasis.

The overexpression and inhibition of miRNA using miRNA mimics and inhibitors, respectively, might be useful for the treatment of tumor metastasis. miR-1908, miR199a-5p and miR-199a-3p promote invasion, angiogenesis and colonization in the case of melanoma by the convergent targeting of ApoE. The therapeutic delivery of locked nucleic acids to silence these aberrantly expressed miRNAs significantly inhibits the metastasis of melanoma to multiple organs. Therefore, multiple prognostic miRNAs with synergistic combinatorial therapeutic potential can be 
used as a treatment for melanoma [92]. Many patients carry a large number of DTCs in their circulation, bone marrow and other distant sites at the time of their initial cancer diagnosis. Therefore, effective anti-metastatic treatment must inhibit the survival and proliferation of metastases that are already established. The induction of miR-31 in already-established metastases triggers pulmonary metastatic regression and extends survival, whereas the acute activation of miR-31 does not affect primary mammary tumor growth. This finding indicates that the restoration of miR-31 function may be used to specifically target metastatic disease [93]. The plasma level of miR-101 is higher in HCC patients without distant metastases compared with those with distant metastases. In an animal model of $\mathrm{HCC}$, the delivery of lentivirus-mediated miR-
101 inhibits HCC growth, intrahepatic metastasis and distant metastasis [94]. The administration of miR-10b antagomirs in mice with highly metastatic cells significantly inhibits lung metastases but does not affect primary mammary tumor growth [95]. Thus, miRNA mimics and inhibitors are potential candidates for the targeting of tumor metastasis.

\section{Conclusions and future perspectives}

Current evidence has demonstrated that various miRNAs play critical roles in the coordination of tumor cell invasion, intravasation, survival, extravasation and/or colonization, as well as EMT, stemness, dormancy and the metastatic microenvironment (Fig. 1) (Table 1). Although metastasis-related miRNAs have opened a

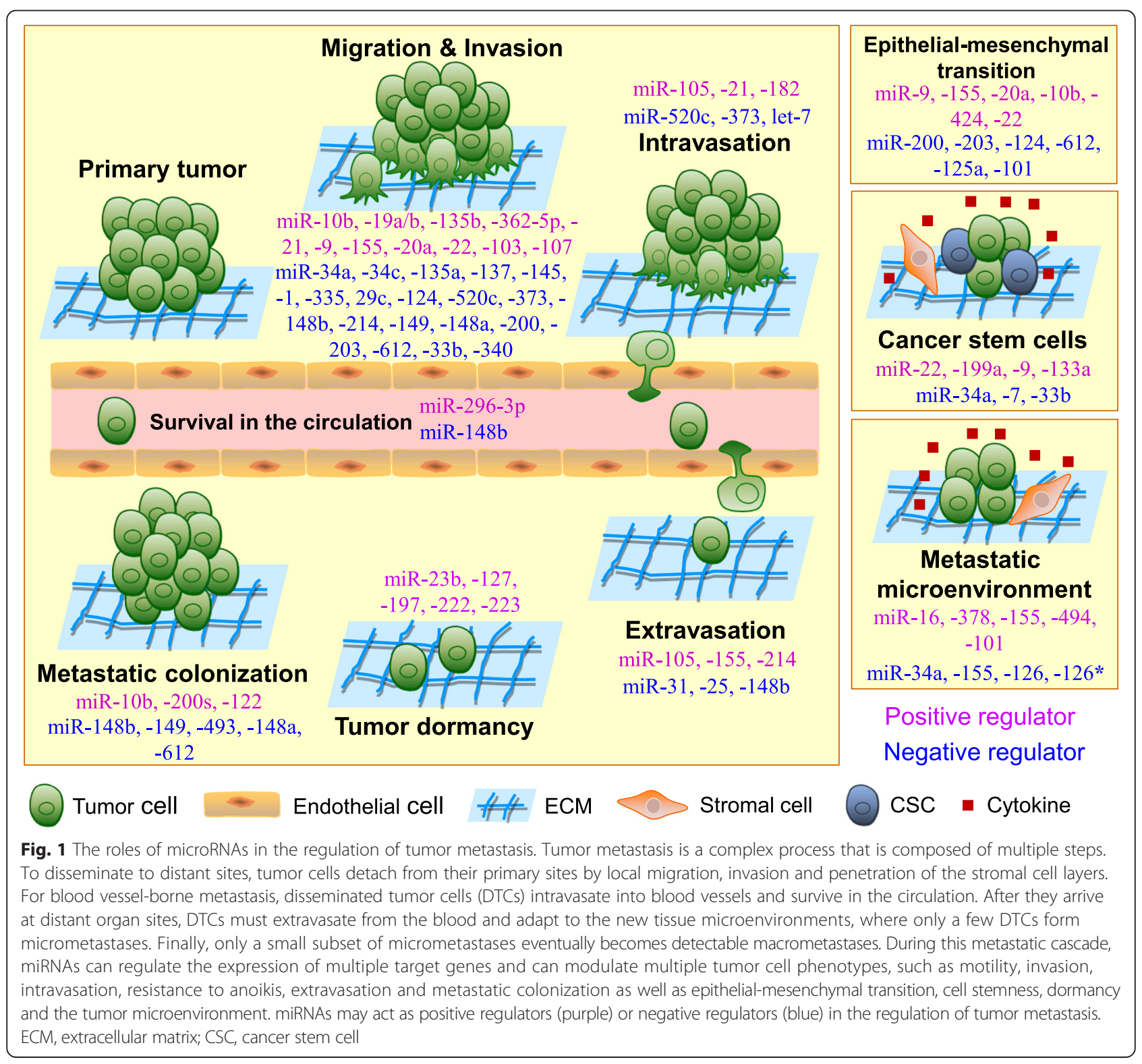


Table 1 Functions of microRNAs in tumor metastasis

\begin{tabular}{|c|c|c|c|}
\hline microRNA & Function in tumor metastasis & Targets and putative targets & References \\
\hline miR-10b & Promotes cell migration, invasion and metastasis & TP53, PAX6, NOTCH1, HOXD10 & {$[11,12]$} \\
\hline miR-19a/b & Promotes gastric cancer cell migration, invasion and metastasis & MXD1 & [13] \\
\hline miR-135b & Promotes cell migration, invasion and metastasis & LATS2, $\beta-\operatorname{TrCP}, \mathrm{NDR} 2, \mathrm{LZTS1}$ & [14] \\
\hline miR-362-5p & $\begin{array}{l}\text { Promotes cell proliferation, migration and invasion in vitro and tumor growth } \\
\text { and metastasis in vivo }\end{array}$ & CYLD & [15] \\
\hline miR-34a & $\begin{array}{l}\text { Inhibits cell migration, invasion and lung metastasis of breast cancer cells; } \\
\text { suppresses prostate CSCs and metastasis; decreases the production of the } \\
\text { chemokine CCL22; disturbs the bone metastatic niche }\end{array}$ & Fra-1, CD44, CCL22, Tgif2 & {$[16,68,72,73]$} \\
\hline $\operatorname{miR}-34 \mathrm{c}$ & Inhibits cell migration, invasion and lung metastasis of breast cancer cells & Fra-1 & [16] \\
\hline miR-135a & Inhibits prostate cancer cell migration and invasion & ROCK1, ROCK2 & [17] \\
\hline miR-137 & Reduces the invasiveness of colorectal cancer cells & FMNL2 & [18] \\
\hline miR-145 & $\begin{array}{l}\text { Attenuates gastric cancer cell migratory and invasive abilities in vitro and } \\
\text { suppresses the metastatic cascade in vivo; inhibits the invasion and metastasis of } \\
\text { neuroblastoma cells }\end{array}$ & N-cadherin, HIF-2a & {$[19,20]$} \\
\hline miR-1 & $\begin{array}{l}\text { Affects the cellular organization of F-actin and impairs tumor cell invasion and } \\
\text { filopodia formation }\end{array}$ & FN1, LASP1, XPO6 & [21] \\
\hline miR-335 & Suppresses cell migration, invasion and metastasis & Tenascin C, SOX4 & [24] \\
\hline miR-29c & Inhibits tumor invasion and metastasis & Collagens, Laminin $\gamma 1$ & [25] \\
\hline miR-21 & $\begin{array}{l}\text { Promotes epithelial collective cell migration, invasion and lung metastasis; } \\
\text { enhances colorectal cancer cell intravasation }\end{array}$ & TPM1, PDCD4, Maspin, PDCD4 & {$[27,30,31]$} \\
\hline miR-124 & $\begin{array}{l}\text { Modulates the intercellular adhesion of leading cells; inhibits EMT in vitro and } \\
\text { suppresses intrahepatic and pulmonary metastasis in vivo }\end{array}$ & Integrin $\beta 1$, ROCK2, EZH2 & {$[28,55]$} \\
\hline miR-105 & Destroys the integrity of vascular endothelial barriers to promote metastasis & ZO-1 & [29] \\
\hline miR-182 & Promotes cancer cell intravasation into the circulation & Mtss1, Pai1, Rsu1, Timp1 & [32] \\
\hline miR-520c/373 & Inhibits cell invasion in vitro and the intravasation of breast cancer cells in vivo & RELA, TGFBR2 & [33] \\
\hline let-7 & Inhibits bone metastasis of breast cancer cells & HMGA2, Snail & [34] \\
\hline miR-296-3p & Promotes prostate cancer cell survival & ICAM-1 & [35] \\
\hline miR-148b & $\begin{array}{l}\text { Inhibits multiple steps of tumor progression via the regulation of invasion, } \\
\text { resistance to anoikis, extravasation, lung metastasis colonization and } \\
\text { chemotherapeutic response }\end{array}$ & $\begin{array}{l}\text { ITGA5, ROCK1, PIK3CA/p110a, } \\
\text { NRAS, CSF1 }\end{array}$ & [36] \\
\hline miR-155 & $\begin{array}{l}\text { Negatively regulates the function of the brain endothelial barrier; promotes } \\
\text { TGF- } \beta \text {-induced EMT, tight junction dissolution, cell migration and invasion. } \\
\text { Suppresses tumor growth via the regulation of the tumor microenvironment }\end{array}$ & $\begin{array}{l}\text { Annexin-2, Claudin-1, DOCK-1, } \\
\text { Syntenin-1, c-Maf, Pu.1, Ship1, } \\
\text { C/EBP } \beta \text {, HIF-1a }\end{array}$ & {$[38,50,76-78]$} \\
\hline miR-214 & $\begin{array}{l}\text { Suppresses cell migration and invasion in vitro and inhibits liver metastasis of } \\
\text { colorectal cancer cells in vivo but promotes migration, invasion and resistance to } \\
\text { anoikis of melanoma cells in vitro and the extravasation and lung metastasis } \\
\text { formation in vivo }\end{array}$ & FGFR1, TFAP2C & [39-41] \\
\hline miR-31 & $\begin{array}{l}\text { Represses local invasion, extravasation and initial survival in distant tissues and } \\
\text { distant metastatic colonization }\end{array}$ & ITGA5, RDX, RhoA & [42] \\
\hline $\operatorname{miR}-25$ & Inhibits extravasation of prostate cancer cells in vivo & av- and a6-integrins & [43] \\
\hline miR-200s & Inhibits EMT but promotes metastatic colonization & Sec23a, ZEB1, ZEB2 & {$[44,52,53]$} \\
\hline miR-122 & Promotes metastatic colonization of breast cancer cells & PKM2 & [45] \\
\hline miR-149 & $\begin{array}{l}\text { Inhibits basal-like breast cancer cell migration and invasion in vitro and impairs } \\
\text { lung colonization in vivo }\end{array}$ & Rap1a, Rap1b & [46] \\
\hline miR-493 & $\begin{array}{l}\text { Inhibits the settlement of metastasized colon cancer cells in the liver; promotes the } \\
\text { death of colon cancer cells }\end{array}$ & IGF1R & [47] \\
\hline miR-148a & $\begin{array}{l}\text { Inhibits hepatoma cell migration in vitro and pulmonary metastatic colonization } \\
\text { in vivo }\end{array}$ & Met & [48] \\
\hline miR-9 & $\begin{array}{l}\text { Promotes breast cancer cell motility and invasiveness; enhances squamous cell } \\
\text { carcinoma CSC expansion and metastasis }\end{array}$ & $\mathrm{CDH} 1$, a-catenin & {$[49,66]$} \\
\hline miR-20a & Induces EMT and promotes metastasis & Smad7 & [51] \\
\hline
\end{tabular}


Table 1 Functions of microRNAs in tumor metastasis (Continued)

\begin{tabular}{|c|c|c|c|}
\hline miR-203 & Suppresses cell invasion and EMT in vitro and lung metastatic colonization in vivo & SNAI2 & [54] \\
\hline miR-612 & Inhibits local invasion and distant metastatic colonization & Akt2 & [56] \\
\hline miR-125a & Inhibits EMT of ovarian cancer cells & ARID3B & {$[58]$} \\
\hline miR-424 & Promotes EMT & TGFBR3 & [60] \\
\hline miR-22 & Promotes EMT, invasiveness, stemness and metastasis & TET1, TET2, TET3 & [64] \\
\hline miR-199a & $\begin{array}{l}\text { Endows breast cancer cells with enhanced CSC properties; promotes invasion, } \\
\text { angiogenesis and colonization in the case of melanoma }\end{array}$ & FOXP2, ApoE & {$[65,92]$} \\
\hline miR-133a & Promotes invasion of CSCs that express high levels of CD133 & SGMS2, UBA2, SNX30, ANXA2 & [67] \\
\hline miR-7 & $\begin{array}{l}\text { Suppresses cell invasion and metastasis; inhibits the ability of breast CSCs to } \\
\text { metastasize to the brain }\end{array}$ & SETDB1, KLF4 & {$[69,70]$} \\
\hline miR-33b & Inhibits the stemness and lung metastasis of breast cancer cells & HMGA2, SALL4, Twist1 & [71] \\
\hline miR-494 & Promotes the accumulation of MDSCs in tumor tissues & PTEN & [81] \\
\hline miR-101 & $\begin{array}{l}\text { Augments cancer cell stemness and enhances the tumorigenic and metastatic } \\
\text { potential of cancer cells; inhibits HCC growth, intrahepatic metastasis and distant } \\
\text { metastasis }\end{array}$ & $\mathrm{CtBP} 2, \mathrm{ROCK} 2$ & {$[82,94]$} \\
\hline miR-126 & $\begin{array}{l}\text { Inhibits endothelial recruitment, metastatic angiogenesis and metastatic } \\
\text { colonization at distant sites }\end{array}$ & $\begin{array}{l}\text { IGFBP2, PITPNC1, MERTK, } \\
\text { SDF-1a }\end{array}$ & {$[83,84]$} \\
\hline $\operatorname{miR}-126^{*}$ & $\begin{array}{l}\text { Suppresses breast cancer metastasis via the inhibition of the recruitment of } \\
\text { mesenchymal stem cells and inflammatory monocytes }\end{array}$ & SDF-1a & [84] \\
\hline $\operatorname{miR}-23 b$ & Promotes breast cancer cell dormancy in a metastatic niche & MARCKS & {$[87]$} \\
\hline $\begin{array}{l}\operatorname{miR}-127 / 197 / \\
222 / 223\end{array}$ & Promotes breast cancer cell quiescence & CXCL12 & {$[88]$} \\
\hline miR-103/107 & Promotes local invasion and liver metastasis & DAPK, KLF4 & [89] \\
\hline
\end{tabular}

new field of research with respect to tumor metastasis, research on the functions and mechanisms of miRNAs in tumor metastasis has only recently begun.

Interestingly, miRNAs in vesicles secreted from highly metastatic tumor cells can be internalized by weakly metastatic cells or stromal cells and subsequently influence the functions of these cells. Conversely, some miRNAs that are secreted from stromal cells can modulate the metastatic ability of DTCs. Thus, secretory miRNAs provide versatile communication between cancer cells and stromal cells and regulate the capacity for tumor growth at metastatic lesions. Moreover, the contextdependent roles of miRNAs in the metastatic cascade often involve multiple regulatory loops. The altered expression of one miRNA can regulate the expression of multiple target genes and modulate multiple cancer cell phenotypes, such as motility, invasion, resistance to anoikis and metastatic colonization. However, little is known about the roles of miRNAs in the regulation of DTC intravasation, circulation and extravasation. In addition, compared with conventional metastasis-related transcription factors, in most cases, miRNAs do not function as master regulators in the hierarchy of gene regulators. miRNAs may behave as critical tuners of transcriptional programs through the coordination of regulatory signaling networks that allow cells to adapt to microenvironmental and intracellular stresses during tumor metastasis. Comparisons of miRNA expression profiles of metastatic tumors in secondary sites with those of corresponding normal tissues and primary tumors have demonstrated that alterations in miRNA expression profiles can serve as phenotypic signatures of particular types of tumor metastasis and of specific steps in the tumor metastatic cascade. Therefore, miRNA expression profiling to screen for miRNAs that may serve as diagnostic or prognostic biomarkers or as therapeutic targets for tumor metastasis has great potential. However, much research is still needed for the development of effective miRNA-targeted therapies. A complete and accurate understanding of the molecular mechanisms of miRNAs in tumor metastasis will reveal invaluable diagnostic and prognostic biomarkers as well as potential targets for the therapeutic intervention of tumor metastasis.

\section{Competing interests}

The authors declare that they have no competing interests.

\section{Authors' contributions}

All authors drafted and approved the manuscript.

\section{Acknowledgements}

This work was supported by grants from the China Postdoctoral Science Foundation (2012M511785, 2013M540530), the National Natural Science Foundation of China $(81201305,81370280,81372841$ and 81471970) and the Fundamental Research Funds for the Central Universities (20720140545). 


\section{Author details}

${ }^{1}$ Fujian Provincial Key Laboratory of Chronic Liver Disease and Hepatocellular Carcinoma, Zhongshan Hospital, Medical College, Xiamen University, Xiamen 361004, China. ${ }^{2}$ Department of Cardiology, The First Affiliated Hospital of Nanjing Medical University, Nanjing 210029, China. ${ }^{3}$ Medical College, Xiamen University, Xiamen 361102, China. ${ }^{4}$ State Key Laboratory of Cellular Stress Biology, Innovation Center for Cell Signaling Network, School of Life Sciences, Xiamen University, Xiamen 361102, China.

\section{Received: 9 May 2015 Accepted: 14 June 2015}

\section{Published online: 20 June 2015}

\section{References}

1. Chaffer CY, Weinberg RA. A perspective on cancer cell metastasis. Science, 2011;331(6024):1559-64.

2. Quail DF, Joyce JA. Microenvironmental regulation of tumor progression and metastasis. Nat Med. 2013;19(11):1423-37.

3. Wan L, Pantel K, Kang Y. Tumor metastasis: moving new biological insights into the clinic. Nat Med. 2013;19(11):1450-64.

4. Ma L, Weinberg RA. Micromanagers of malignancy: role of microRNAs in regulating metastasis. Trends Genet. 2008;24(9):448-56.

5. Ruan K, Fang X, Ouyang G. MicroRNAs: novel regulators in the hallmarks of human cancer. Cancer Lett. 2009;285(2):116-26.

6. Inui M, Martello G, Piccolo S. MicroRNA control of signal transduction. Nat Rev Mol Cell Biol. 2010;11(4):252-63.

7. Sieuwerts AM, Mostert B, Bolt-de Vries J, Peeters D, de Jongh FE, Stouthard $J M$, et al. mRNA and microRNA expression profiles in circulating tumor cells and primary tumors of metastatic breast cancer patients. Clin Cancer Res. 2011;17(11):3600-18.

8. Volinia S, Galasso M, Sana ME, Wise TF, Palatini J, Huebner K, et al. Breast cancer signatures for invasiveness and prognosis defined by deep sequencing of microRNA. Proc Natl Acad Sci U S A. 2012;109(8):3024-9.

9. Alečković M, Kang Y. Regulation of cancer metastasis by cell-free miRNAs. Biochim Biophys Acta. 2014;1855(1):24-42.

10. Zhang $Y$, Yang $P$, Wang XF. Microenvironmental regulation of cancer metastasis by miRNAs. Trends Cell Biol. 2014;24(3):153-60.

11. Ma L, Teruya-Feldstein J, Weinberg RA. Tumour invasion and metastasis initiated by microRNA-10b in breast cancer. Nature. 2007;449(7163):682-8.

12. Lin J, Teo S, Lam DH, Jeyaseelan K, Wang S. MicroRNA-10b pleiotropically regulates invasion, angiogenicity and apoptosis of tumor cells resembling mesenchymal subtype of glioblastoma multiforme. Cell Death Dis. 2012;3:e398.

13. Wu Q, Yang Z, An Y, Hu H, Yin J, Zhang P, et al. MiR-19a/b modulate the metastasis of gastric cancer cells by targeting the tumour suppressor MXD1. Cell Death Dis. 2014;5:e1144.

14. Lin CW, Chang YL, Chang YC, Lin JC, Chen CC, Pan SH, et al. MicroRNA-135b promotes lung cancer metastasis by regulating multiple targets in the Hippo pathway and LZTS1. Nat Commun. 2013:4:1877.

15. Ni F, Zhao H, Cui H, Wu Z, Chen L, Hu Z, et al. MicroRNA-362-5p promotes tumor growth and metastasis by targeting CYLD in hepatocellular carcinoma. Cancer Lett. 2015:356(2 Pt B):809-18.

16. Yang S, Li Y, Gao J, Zhang T, Li S, Luo A, et al. MicroRNA-34 suppresses breast cancer invasion and metastasis by directly targeting Fra-1. Oncogene. 2013;32(36):4294-303.

17. Kroiss A, Vincent S, Decaussin-Petrucci M, Meugnier E, Viallet J, Ruffion A, et al. Androgen-regulated microRNA-135a decreases prostate cancer cell migration and invasion through downregulating ROCK1 and ROCK2. Oncogene 2015;34(22):2846-55.

18. Liang L, Li X, Zhang X, Lv Z, He G, Zhao W, et al. MicroRNA-137, an HMGA1 target, suppresses colorectal cancer cell invasion and metastasis in mice by directly targeting FMNL2. Gastroenterology. 2013;144(3):624-35.

19. Gao P, Xing AY, Zhou GY, Zhang TG, Zhang JP, Gao C, et al. The molecular mechanism of microRNA-145 to suppress invasion-metastasis cascade in gastric cancer. Oncogene. 2013;32(4):491-501.

20. Zhang H, Pu J, Qi T, Qi M, Yang C, Li S, et al. MicroRNA-145 inhibits the growth, invasion, metastasis and angiogenesis of neuroblastoma cells through targeting hypoxia-inducible factor 2 alpha. Oncogene. 2014:33(3):387-97.

21. Hudson RS, Yi M, Esposito D, Watkins SK, Hurwitz AA, Yfantis HG, et al. MicroRNA-1 is a candidate tumor suppressor and prognostic marker in human prostate cancer. Nucleic Acids Res. 2012;40(8):3689-703.
22. Wang Z, Ouyang G. Periostin: a bridge between cancer stem cells and their metastatic niche. Cell Stem Cell. 2012:10(2):111-2.

23. Liu AY, Zheng H, Ouyang G. Periostin, a multifunctional matricellular protein in inflammatory and tumor microenvironments. Matrix Biol. 2014;37:150-6.

24. Tavazoie SF, Alarcón C, Oskarsson T, Padua D, Wang Q, Bos PD, et al. Endogenous human microRNAs that suppress breast cancer metastasis. Nature. 2008;451(7175):147-52.

25. Sengupta S, den Boon JA, Chen IH, Newton MA, Stanhope SA, Cheng YJ, et al. MicroRNA 29c is down-regulated in nasopharyngeal carcinomas, up-regulating mRNAs encoding extracellular matrix proteins. Proc Natl Acad Sci U S A. 2008;105(15):5874-8.

26. Lu M, Jolly MK, Levine H, Onuchic JN, Ben-Jacob E. MicroRNA-based regulation of epithelial-hybrid-mesenchymal fate determination. Proc Natl Acad Sci U S A. 2013;110(45):18144-9.

27. Dean ZS, Riahi R, Wong PK. Spatiotemporal dynamics of microRNA during epithelial collective cell migration. Biomaterials. 2014;37:156-63.

28. Kato T, Enomoto A, Watanabe T, Haga H, Ishida S, Kondo Y, et al. TRIM27/MRTF-B-dependent integrin $\beta 1$ expression defines leading cells in cancer cell collectives. Cell Rep. 2014;7(4):1156-67.

29. Zhou W, Fong MY, Min Y, Somlo G, Liu L, Palomares MR, et al. Cancer-secreted miR-105 destroys vascular endothelial barriers to promote metastasis. Cancer Cell. 2014;25(4):501-15.

30. Zhu S, Wu H, Wu F, Nie D, Sheng S, Mo YY. MicroRNA-21 targets tumor suppressor genes in invasion and metastasis. Cell Res. 2008;18(3):350-9.

31. Asangani IA, Rasheed SA, Nikolova DA, Leupold JH, Colburn NH, Post S, et al. MicroRNA-21 (miR-21) post-transcriptionally downregulates tumor suppressor Pdcd4 and stimulates invasion, intravasation and metastasis in colorectal cancer. Oncogene. 2008;27(15):2128-36.

32. Sachdeva M, Mito JK, Lee CL, Zhang M, Li Z, Dodd RD, et al. MicroRNA-182 drives metastasis of primary sarcomas by targeting multiple genes. J Clin Invest. 2014;124(10):4305-19.

33. Keklikoglou I, Koerner C, Schmidt C, Zhang JD, Heckmann D, Shavinskaya A, et al. MicroRNA-520/373 family functions as a tumor suppressor in estrogen receptor negative breast cancer by targeting NF-KB and TGF- $\beta$ signaling pathways. Oncogene. 2012;31(37):4150-63.

34. Dangi-Garimella S, Yun J, Eves EM, Newman M, Erkeland SJ, Hammond SM, et al. Raf kinase inhibitory protein suppresses a metastasis signalling cascade involving LIN28 and let-7. EMBO J. 2009;28(4):347-58.

35. Liu X, Chen Q, Yan J, Wang Y, Zhu C, Chen C, et al. MiRNA-296-3p-ICAM-1 axis promotes metastasis of prostate cancer by possible enhancing survival of natural killer cell-resistant circulating tumour cells. Cell Death Dis. 2013;4:e928.

36. Cimino D, De Pittà C, Orso F, Zampini M, Casara S, Penna E, et al. miR148b is a major coordinator of breast cancer progression in a relapse-associated microRNA signature by targeting ITGA5, ROCK1, PIK3CA, NRAS, and CSF1. FASEB J. 2013;27(3):1223-35.

37. Kong W, He L, Richards EJ, Challa S, Xu CX, Permuth-Wey J, et al. Upregulation of miRNA-155 promotes tumour angiogenesis by targeting $\mathrm{VHL}$ and is associated with poor prognosis and triple-negative breast cancer. Oncogene. 2014;33(6):679-89.

38. Lopez-Ramirez MA, Wu D, Pryce G, Simpson JE, Reijerkerk A, King-Robson J, et al. MicroRNA-155 negatively affects blood-brain barrier function during neuroinflammation. FASEB J. 2014;28(6):2551-65

39. Chen DL, Wang ZQ, Zeng ZL, Wu WJ, Zhang DS, Luo HY, et al. Identification of microRNA-214 as a negative regulator of colorectal cancer liver metastasis by way of regulation of fibroblast growth factor receptor 1 expression. Hepatology. 2014;60(2):598-609.

40. Penna E, Orso F, Cimino D, Vercellino I, Grassi E, Quaglino E, et al. miR-214 coordinates melanoma progression by upregulating ALCAM through TFAP2 and miR-148b downmodulation. Cancer Res. 2013;73(13):4098-111.

41. Penna E, Orso F, Cimino D, Tenaglia E, Lembo A, Quaglino E, et al. microRNA-214 contributes to melanoma tumour progression through suppression of TFAP2C. EMBO J. 2011;30(10):1990-2007.

42. Valastyan S, Chang A, Benaich N, Reinhardt F, Weinberg RA. Concurrent suppression of integrin alpha5, radixin, and RhoA phenocopies the effects of miR-31 on metastasis. Cancer Res. 2010;70(12):5147-54.

43. Zoni $E$, van der Horst $G$, van de Merbel AF, Chen L, Rane JK, Pelger RC, et al. miR-25 modulates invasiveness and dissemination of human prostate cancer cells via regulation of av- and a6 integrin expression. Cancer Res. 2015;75(11):2326-36. 
44. Korpal M, Ell BJ, Buffa FM, Ibrahim T, Blanco MA, Celià-Terrassa T, et al. Direct targeting of Sec23a by miR-200 s influences cancer cell secretome and promotes metastatic colonization. Nat Med. 2011;17(9):1101-8.

45. Fong MY, Zhou W, Liu L, Alontaga AY, Chandra M, Ashby J, et al. Breastcancer-secreted miR-122 reprograms glucose metabolism in premetastatic niche to promote metastasis. Nat Cell Biol. 2015;17(2):183-94.

46. Bischoff A, Huck B, Keller B, Strotbek M, Schmid S, Boerries M, et al. miR149 functions as a tumor suppressor by controlling breast epithelial cell migration and invasion. Cancer Res. 2014;74(18):5256-65.

47. Okamoto K, Ishiguro T, Midorikawa Y, Ohata H, Izumiya M, Tsuchiya N, et al. miR-493 induction during carcinogenesis blocks metastatic settlement of colon cancer cells in liver. EMBO J. 2012;31(7):1752-63.

48. Zhang JP, Zeng C, Xu L, Gong J, Fang JH, Zhuang SM. MicroRNA-148a suppresses the epithelial-mesenchymal transition and metastasis of hepatoma cells by targeting Met/Snail signaling. Oncogene. 2014;33(31):4069-76.

49. Ma L, Young J, Prabhala H, Pan E, Mestdagh P, Muth D, et al. miR-9, a MYC/MYCN-activated microRNA, regulates E-cadherin and cancer metastasis. Nat Cell Biol. 2010;12(3):247-56.

50. Kong W, Yang H, He L, Zhao JJ, Coppola D, Dalton WS, et al. MicroRNA-155 is regulated by the transforming growth factor beta/Smad pathway and contributes to epithelial cell plasticity by targeting RhoA. Mol Cell Biol. 2008;28(22):6773-84.

51. Chang Y, Liu C, Yang J, Liu G, Feng F, Tang J, et al. MiR-20a triggers metastasis of gallbladder carcinoma. J Hepatol. 2013;59(3):518-27.

52. Park SM, Gaur AB, Lengyel E, Peter ME. The miR-200 family determines the epithelial phenotype of cancer cells by targeting the E-cadherin repressors ZEB1 and ZEB2. Genes Dev. 2008;22(7):894-907.

53. Gregory PA, Bert AG, Paterson EL, Barry SC, Tsykin A, Farshid G, et al. The miR-200 family and miR-205 regulate epithelial to mesenchymal transition by targeting ZEB1 and SIP1. Nat Cell Biol. 2008;10(5):593-601.

54. Ding X, Park SI, MCCauley LK, Wang CY. Signaling between transforming growth factor $\beta$ (TGF- $\beta$ ) and transcription factor SNAI2 represses expression of microRNA miR-203 to promote epithelial-mesenchymal transition and tumor metastasis. J Biol Chem. 2013;288(15):10241-53.

55. Zheng F, Liao YJ, Cai MY, Liu YH, Liu TH, Chen SP, et al. The putative tumour suppressor microRNA-124 modulates hepatocellular carcinoma cell aggressiveness by repressing ROCK2 and EZH2. Gut. 2012;61(2):278-89.

56. Tao $Z H$, Wan $J$, Zeng $L Y$, Xie L, Sun HC, Qin $L X$, et al. miR-612 suppresses the invasive-metastatic cascade in hepatocellular carcinoma. J Exp Med. 2013;210(4):789-803.

57. Tatsumi N, Hojo N, Yamada O, Ogawa M, Katsura Y, Kawata S, et al. Deficiency in WT1-targeting microRNA-125a leads to myeloid malignancies and urogenital abnormalities. Oncogene. 2015. doi:10.1038/onc.2015.154.

58. Cowden Dahl KD, Dahl R, Kruichak JN, Hudson LG. The epidermal growth factor receptor responsive miR-125a represses mesenchymal morphology in ovarian cancer cells. Neoplasia. 2009;11(11):1208-15.

59. Tsai JH, Donaher JL, Murphy DA, Chau S, Yang J. Spatiotemporal regulation of epithelial-mesenchymal transition is essential for squamous cell carcinoma metastasis. Cancer Cell. 2012;22(6):725-36.

60. Drasin DJ, Guarnieri AL, Neelakantan D, Kim J, Cabrera JH, Wang CA, et al. TWIST1-induced microRNA-424 reversibly drives mesenchymal programming while inhibiting tumor initiation. Cancer Res. 2015;75(9):1908-21.

61. Gupta PB, Chaffer CL, Weinberg RA. Cancer stem cells: mirage or reality? Nat Med. 2009;15(9):1010-2.

62. Qiu H, Fang X, Luo Q, Ouyang G. Cancer stem cells: a potential target for cancer therapy. Cell Mol Life Sci. 2015. doi:10.1007/s00018-015-1920-4.

63. Iliou MS, da Silva-Diz V, Carmona FJ, Ramalho-Carvalho J, Heyn H, Villanueva A, et al. Impaired DICER1 function promotes stemness and metastasis in colon cancer. Oncogene. 2014;33(30):4003-15.

64. Song SJ, Poliseno L, Song MS, Ala U, Webster K, Ng C, et al. MicroRNAantagonism regulates breast cancer stemness and metastasis via TETfamily-dependent chromatin remodeling. Cell. 2013;154(2):311-24.

65. Cuiffo BG, Campagne A, Bell GW, Lembo A, Orso F, Lien EC, et al. MSCregulated microRNAs converge on the transcription factor FOXP2 and promote breast Cancer metastasis. Cell Stem Cell. 2014;15(6):762-74.

66. White RA, Neiman JM, Reddi A, Han G, Birlea S, Mitra D, et al. Epithelial stem cell mutations that promote squamous cell carcinoma metastasis. J Clin Invest. 2013;123(10):4390-404.

67. Fujiwara T, Katsuda T, Hagiwara K, Kosaka N, Yoshioka Y, Takahashi RU, et al. Clinical relevance and therapeutic significance of microRNA-133a expression profiles and functions in malignant osteosarcoma-initiating cells. Stem Cells. 2014;32(4):959-73.

68. Liu C, Kelnar K, Liu B, Chen X, Calhoun-Davis T, Li H, et al. The microRNA miR-34a inhibits prostate cancer stem cells and metastasis by directly repressing CD44. Nat Med. 2011;17(2):211-5.

69. Zhang H, Cai K, Wang J, Wang X, Cheng K, Shi F, et al. MiR-7, inhibited indirectly by lincRNA HOTAIR, directly inhibits SETDB1 and reverses the EMT of breast cancer stem cells by downregulating the STAT3 pathway. Stem Cells. 2014;32(11):2858-68.

70. Okuda H, Xing F, Pandey PR, Sharma S, Watabe M, Pai SK, et al. miR-7 suppresses brain metastasis of breast cancer stem-like cells by modulating KLF4. Cancer Res. 2013;73(4):1434-44.

71. Lin Y, Liu AY, Fan C, Zheng H, Li Y, Zhang C, et al. MicroRNA-33b inhibits breast cancer metastasis by targeting HMGA2, SALL4 and Twist1. Sci Rep. 2015;5:9995

72. Yang P, Li QJ, Feng Y, Zhang Y, Markowitz GJ, Ning S, et al. TGF- $\beta$-miR-34aCCL22 signaling-induced Treg cell recruitment promotes venous metastases of HBV-positive hepatocellular carcinoma. Cancer Cell. 2012;22(3):291-303.

73. Krzeszinski JY, Wei W, Huynh H, Jin Z, Wang X, Chang TC, et al. miR-34a blocks osteoporosis and bone metastasis by inhibiting osteoclastogenesis and Tgif2. Nature. 2014;512(7515):431-5.

74. Ell B, Mercatali L, Ibrahim T, Campbell N, Schwarzenbach H, Pantel K, et al. Tumor-induced osteoclast miRNA changes as regulators and biomarkers of osteolytic bone metastasis. Cancer Cell. 2013;24(4):542-56.

75. Rodriguez A, Vigorito E, Clare S, Warren MV, Couttet P, Soond DR, et al. Requirement of bic/microRNA-155 for normal immune function. Science. 2007;316(5824):608-11.

76. Zonari E, Pucci F, Saini M, Mazzieri R, Politi LS, Gentner B, et al. A role for miR-155 in enabling tumor-infiltrating innate immune cells to mount effective antitumor responses in mice. Blood. 2013;122(2):243-52.

77. Yu F, Jia X, Du F, Wang J, Wang Y, Ai W, et al. miR-155-deficient bone marrow promotes tumor metastasis. Mol Cancer Res. 2013;11(8):923-36.

78. Wang J, Yu F, Jia X, Iwanowycz S, Wang Y, Huang S, et al. MicroRNA-155 deficiency enhances the recruitment and functions of myeloid-derived suppressor cells in tumor microenvironment and promotes solid tumor growth. Int J Cancer. 2015;136(6):E602-13.

79. Cui B, Chen L, Zhang S, Mraz M, Fecteau JF, Yu J, et al. MicroRNA-155 influences B-cell receptor signaling and associates with aggressive disease in chronic lymphocytic leukemia. Blood. 2014;124(4):546-54.

80. Cheng CJ, Bahal R, Babar IA, Pincus Z, Barrera F, Liu C, et al. MicroRNA silencing for cancer therapy targeted to the tumour microenvironment. Nature. 2015;518(7537):107-10.

81. Liu Y, Lai L, Chen Q, Song Y, Xu S, Ma F, et al. MicroRNA-494 is required for the accumulation and functions of tumor-expanded myeloid-derived suppressor cells via targeting of PTEN. J Immunol. 2012;188(11):5500-10.

82. Cui TX, Kryczek I, Zhao L, Zhao E, Kuick R, Roh MH, et al. Myeloid-derived suppressor cells enhance stemness of cancer cells by inducing microRNA101 and suppressing the corepressor CtBP2. Immunity. 2013;39(3):611-21.

83. Png KJ, Halberg N, Yoshida M, Tavazoie SF. A microRNA regulon that mediates endothelial recruitment and metastasis by cancer cells. Nature. 2011;481(7380):190-4.

84. Zhang Y, Yang P, Sun T, Li D, Xu X, Rui Y, et al. miR-126 and miR-126* repress recruitment of mesenchymal stem cells and inflammatory monocytes to inhibit breast cancer metastasis. Nat Cell Biol. 2013;15(3):284-94.

85. Ghajar CM, Peinado H, Mori H, Matei IR, Evason KJ, Brazier H, et al. The perivascular niche regulates breast tumour dormancy. Nat Cell Biol. 2013;15(7):807-17.

86. Wu T, Ouyang G. Matricellular proteins: multifaceted extracellular regulators in tumor dormancy. Protein Cell. 2014;5(4):249-52.

87. Ono M, Kosaka N, Tominaga N, Yoshioka Y, Takeshita F, Takahashi RU, et al. Exosomes from bone marrow mesenchymal stem cells contain a microRNA that promotes dormancy in metastatic breast cancer cells. Sci Signal. 2014;7(332):ra63.

88. Lim PK, Bliss SA, Patel SA, Taborga M, Dave MA, Gregory LA, et al. Gap junction-mediated import of microRNA from bone marrow stromal cells can elicit cell cycle quiescence in breast cancer cells. Cancer Res. 2011;71(5):1550-60.

89. Chen HY, Lin YM, Chung HC, Lang YD, Lin CJ, Huang J, et al. miR-103/107 promote metastasis of colorectal cancer by targeting the metastasis suppressors DAPK and KLF4. Cancer Res. 2012;72(14):3631-41. 
90. Takeyama H, Yamamoto H, Yamashita S, Wu X, Takahashi H, Nishimura J, et al. Decreased miR-340 expression in bone marrow is associated with liver metastasis of colorectal cancer. Mol Cancer Ther. 2014;13(4):976-85.

91. Corcoran C, Rani S, Breslin S, Gogarty M, Ghobrial IM, Crown J, et al. miR-630 targets IGF1R to regulate response to HER-targeting drugs and overall cancer cell progression in HER2 over-expressing breast cancer. Mo Cancer. 2014;13:71.

92. Pencheva N, Tran H, Buss C, Huh D, Drobnjak M, Busam K, et al. Convergent multi-miRNA targeting of ApoE drives LRP1/LRP8-dependent melanoma metastasis and angiogenesis. Cell. 2012;151(5):1068-82.

93. Valastyan S, Chang A, Benaich N, Reinhardt F, Weinberg RA. Activation of miR-31 function in already-established metastases elicits metastatic regression. Genes Dev. 2011:25(6):646-59.

94. Zheng F, Liao YJ, Cai MY, Liu TH, Chen SP, Wu PH, et al. Systemic delivery of microRNA-101 potently inhibits hepatocellular carcinoma in vivo by repressing multiple targets. PLoS Genet. 2015;11(2):e1004873.

95. Ma L, Reinhardt F, Pan E, Soutschek J, Bhat B, Marcusson EG, et al.

Therapeutic silencing of miR-10b inhibits metastasis in a mouse mammary tumor model. Nat Biotechnol. 2010;28(4):341-7.

\section{Submit your next manuscript to BioMed Central and take full advantage of:}

- Convenient online submission

- Thorough peer review

- No space constraints or color figure charges

- Immediate publication on acceptance

- Inclusion in PubMed, CAS, Scopus and Google Scholar

- Research which is freely available for redistribution 